\title{
Rhabdomyosarcoma with Posterior Paresis and Megaesophagus in a Holstein Heifer
}

\author{
Ayano KAJIWARA ${ }^{1)}$, Natsumi TANI'2), Yoshiyasu KOBAYASHI'), Hidefumi FURUOKA ${ }^{2}$, \\ Naoki SASAKI ${ }^{2)}$, Mitsuo ISHII ${ }^{2)}$ and Hisashi INOKUMA ${ }^{2) *}$ \\ ${ }^{1)}$ Tokachi Agricultural Mutual Aid Association, Kawanishi, Obihiro 089-1182 and ${ }^{2}$ School of Veterinary Medicine, Obihiro University of \\ Agriculture and Veterinary Medicine, Inada-cho, Obihiro, Hokkaido, 080-8555, Japan
}

(Received 5 November 2008/Accepted 29 January 2009)

ABSTRACT. A 7-month-old Holstein heifer presented with posterior paresis and megaesophagus. At post mortem examination, a nodular tumor was found attached to the thoracic wall and the eighth to eleventh thoracic vertebrae, adjacent to the left posterior pulmonary lobe. The tumor was diagnosed as rhabdomyosarcoma by histology. This is a very rare case of spinal infiltration of rhabdomyosarcoma in cattle.

KEY WORDS: cattle, megaesophagus, posterior paresis, rhabdomyosarcoma.

J. Vet. Med. Sci. 71(6): 827-829, 2009

Acute or subacute bovine posterior paresis is commonly caused by physical injury to bones, muscles, joints, or subsequent spinal injury. Tumors occur only rarely in spinal cords of cattle, and little information is available about posterior paresis caused by tumor invasion $[2,7]$. Rhabdomyosarcomas are highly-invasive and metastatic malignant tumors arising in soft tissue and have been reported in various animals, including humans. In cattle, the incidence of rhabdomyosarcoma is very low and few case reports have documented its symptoms, which can include massive tumor formation in the body cavities, loss of appetite, and diarrhea $[1,4,5]$. There have been no reports of posterior paresis or megaesophagus in cattle with rhabdomyosarcoma. Here, we present the first known case of a Holstein heifer with rhabdomyosarcoma accompanied by megaesophagus and posterior paresis.

The 7-month-old Holstein heifer with astasia-abasia was first examined on May 1, 2006 (first day of illness). At the initial examination, the heifer had a body temperature of $38.5^{\circ} \mathrm{C}$, heart rate of $100 \mathrm{bpm}$, and respiratory rate of 60 breaths $/ \mathrm{min}$. The heifer was emaciated and had a prominent jugular vein; it was able to stand up and walk only with assistance. Despite treatment with antibiotics, vitamin B1, and fluid replacement, the heifer could not stand on its own and was taken to Obihiro University of Agriculture and Veterinary Medicine on the tenth day of illness.

Upon admission, rectal temperature was $37.5^{\circ} \mathrm{C}$, heart rate was $69 \mathrm{bpm}$ and respiratory rate was 26 breaths $/ \mathrm{min}$; heart murmur and arrhythmia were not detected. One to two ruminal movements were observed per minute. The heifer was severely dehydrated, but visible mucous membranes were normal and surface lymph nodes were not enlarged. When we attempted to help the heifer to stand, the heifer could raise its forelimbs, but its weak hindlimbs buckled. The flexion and patellar reflexes of the left and right hindlimbs were normal. Mastication caused exaggerated esoph-

\footnotetext{
* Correspondence to: Inokuma, H., Obihiro University of Agriculture and Veterinary Medicine, Inada, Obihiro, 080-8555 Japan. e-mail: inokuma@obihiro.ac.jp
}

ageal movements, and air movements were detected by thoracic auscultation. Therefore, megaesophagus was suspected and a barium esophagography was performed. Megaesophagus was confirmed, but no constriction was observed.

Blood test on that day showed increased red blood cells $\left(10.11 \times 10^{6} / \mu \mathrm{L}\right)$ and packed cell volume $(32 \%)$. Biochemical examination of blood revealed markedly increased creatine phosphokinase (2036 U/L) and moderately increased aspartate aminotransferase $(305 \mathrm{U} / \mathrm{L})$. With regard to serum electrolytes, sodium $(125 \mathrm{mEq} / \mathrm{L})$ and chloride $(85 \mathrm{mEq} / \mathrm{L})$ levels were markedly low. Serum levels of vitamin E (110 $\mu \mathrm{g} / \mathrm{dL})$ and selenium $(8.3 \mu \mathrm{g} / \mathrm{dL})$ ruled out nutritional myopathy (white muscle disease).

Fluid replacement therapy was initiated because the heifer had difficulty eating and drinking on its own, but the heifer's general condition did not improve. The animal was euthanized and pathological examinations were performed on day 19 of the illness.

Gross examination revealed a nodular tumor (diameter, approximately $15 \mathrm{~cm}$ ) attached to the thoracic wall and the eighth to eleventh thoracic vertebrae, adjacent to the left posterior pulmonary lobe (Fig. 1). The esophagus did not appear to be compressed by the tumor mass. However, the tumor invaded the spinal canal, compressing the left foramen of the tenth thoracic vertebra to the tenth thoracic nerve and the caudal side of the ninth thoracic vertebra to the cranial side of the eleventh thoracic vertebra (Fig. 2).

Osteolysis was confirmed in the ventral side of the spinal canal of the tenth thoracic vertebra. Masses of food had accumulated in the dilated esophagus, and a large volume ascites was found, with numerous nodules 1 to $5 \mathrm{~cm}$ in diameter scattered throughout the omentum. Most nodules were white, but red nodules were also detected.

Tumor tissues on the both the thoracic wall and omentum consisted of diffuse growth of small round tumor cells, spindle-shaped cells with nuclear chains, and relatively large polymorphic giant cells (Fig. 3A). The tumor invaded the adjacent tissue, but the mitotic rate of the tumor cells was 


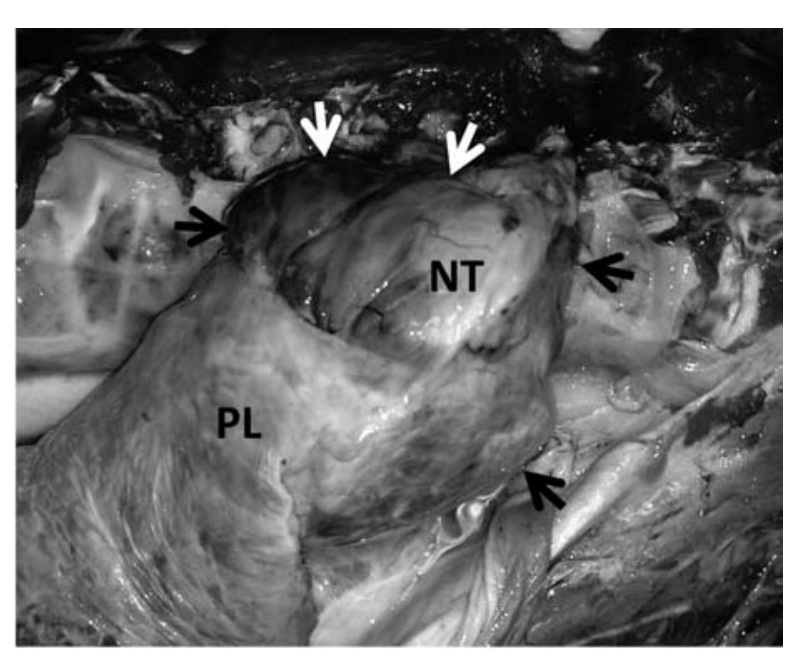

Fig. 1. The nodular tumor (NT, black and white arrows) attached to the thoracic wall and the eighth to eleventh thoracic vertebrae, adjacent to the left posterior pulmonary lobe (PL). The esophagus did not appear to be compressed by the tumor mass (diameter, approximately $15 \mathrm{~cm}$ ).

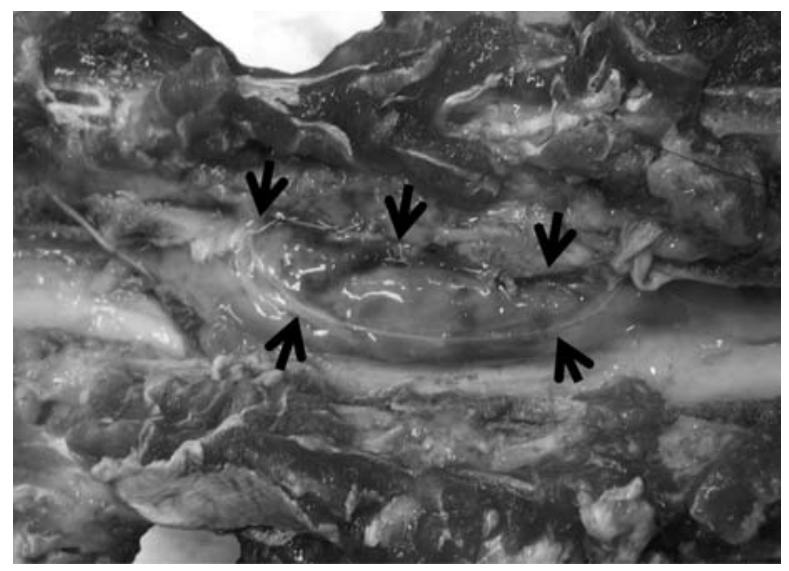

Fig. 2. Caudal side of the ninth thoracic vertebra to the cranial side of the eleventh thoracic vertebra. Spinal canal was compressed and constricted by the epidural tumor (arrows).

relatively low. Cross-striations were detected in some spindle tumor cells by phosphotungstic acid-hematoxylin (PTAH) staining (Fig. 3B). Immunohistological analysis revealed that the tumor cells were positive for myoglobin, desmin, and vimentin. The tumor was diagnosed as rhabdomyosarcoma. Distributional pattern of tumor tissues was quite unique; the large mass was localized on the thoracic walls, whereas the small masses were scattered on the omentum. Thus the primary site of the tumor remained unclear.

Histopathological examination also revealed white matter degeneration as indicated by axonal swelling and macrophage infiltration in the area of spinal cord compression (Fig. 4). Central chromatolysis was also detected in motor neurons in the ventral horn.
In the present case, posterior paresis, the predominant symptom, was believed to be caused by rhabdomyosarcoma invading the thoracic spinal canal, compressing the ninth to eleventh thoracic vertebrae. Rhabdomyosarcoma is a highly invasive malignant tumor and invasion of the thoracic cord has previously been reported in humans and cats $[3,8]$. To the best of our knowledge, there has been no report of spinal invasion in cattle. Because past cases of bovine rhabdomyosarcoma occurred in mature cattle $[1,4,5]$, rhabdomyosarcoma is believed to be rare in calves [6]. Therefore, the present case of a 7-month-old heifer with rhabdomyosarcoma is thought to be extremely unusual.

The nerves that control the forelimbs (musculocutaneous, suprascapular, axillary, median, ulnar, and radial nerves) originate from the sixth cervical vertebra to the second thoracic vertebra, and the nerves that control the hindlimbs (femoral, tibial, and common fibular nerves) originate from the caudal vertebrae to the fourth lumbar vertebra. Compressing the ninth to eleventh thoracic vertebrae does not affect normal spinal reflex in the forelimbs, but leads to progressive upper motor neuron dysfunction in the hindlimbs. However, in the present case, a neurological test conducted on day 10 of the illness did not detect a change in flexion or patella reflexes in the hindlimbs. Because astasia-abasia lasted for more than ten days and the blood level of creatine phosphokinase was high, spinal reflexes may not have been accurately assessed due to muscular atrophy or injury to the hindlimbs.

Megaesophagus was another symptom in the present case, but neither physical compression nor obstruction of the esophagus by the thoracic tumor was detected. Thus, we concluded that vagal nerve injury by the thoracic tumor caused abnormal esophageal movements that led to megaesophagus. Moreover, difficulty swallowing resulting from megaesophagus may have caused the dehydration and emaciation of the heifer.

Acute or subacute posterior paresis in heifers is generally caused by bone, muscle, and joint injury from fractures and dislocations, or subsequent spinal injuries. However, medical history and findings indicated no such injury in the present case; therefore, the cause of posterior paresis could not be ascertained at the initial examination. Tumors are suspected as the cause of posterior paresis in heifers in the presence of signs such as superficial lymph node enlargement and tumors, palpable tumor at rectal examination, or suspected bovine leukemia. Although surface lymph node enlargement and hematological abnormalities were absent in the present case, abnormal esophageal movements and megaesophagus indicated a thoracic tumor. In conclusion, this is a very rare case of spinal infiltration of rhabdomyosarcoma found in a 7-month-old heifer.

ACKNOWLEDGEMENT. This work was supported in part by the Tokachi Agriculture Mutual Aid Association, and Education and Research Grant under the President's Discretion of Obihiro University. 


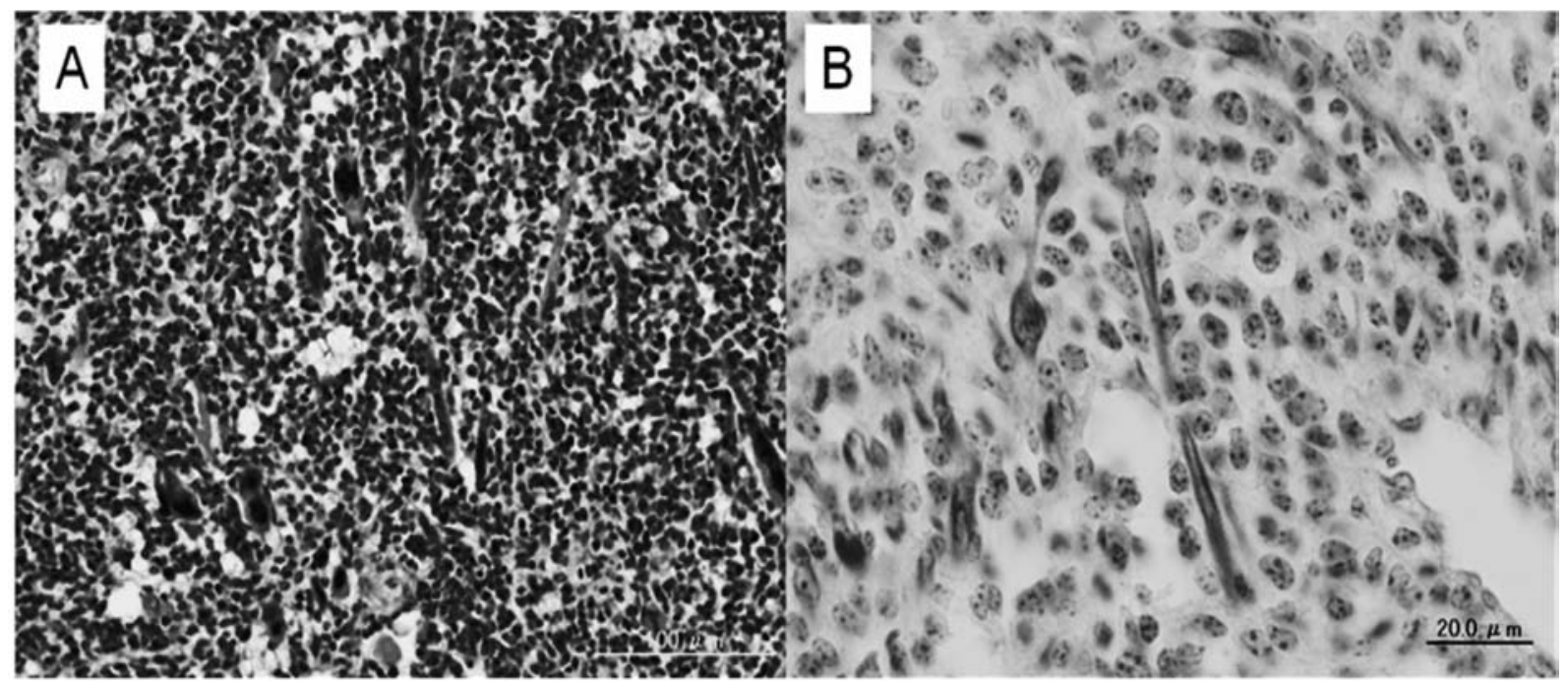

Fig. 3. Macrophotograph of tumor tissues (A) Tumor tissue on thoracic wall and omentum consisted of diffuse growth of small round tumor cells, and was interspersed among spindle-shaped cells. Spindle-shaped cells have nuclear chains. Hematoxylin eosin stain. (B) Cross striations were observed in some spindle tumor cells by PTAH staining.

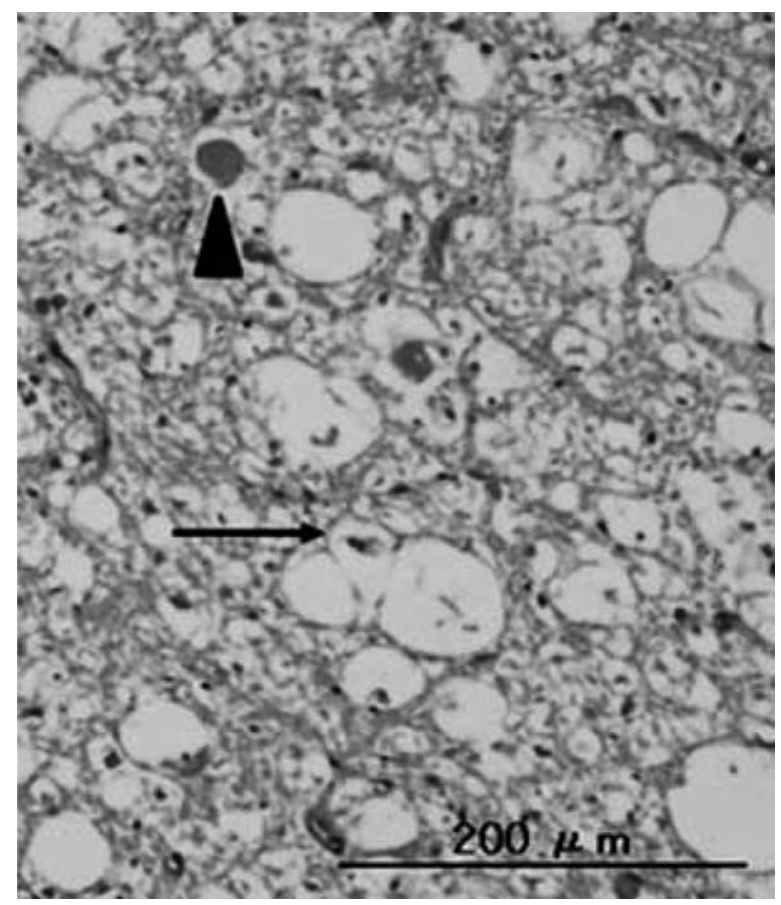

Fig. 4. Macrophotograph of spinal cord at the area of spinal cord compression. Note the marked white matter degeneration indicated by axonal swelling (arrow head) and macrophage infiltration (arrow). Hematoxylin eosin stain.

\section{REFERENCES}

1. Aoyagi, T., Saruta, K., Asahi, I., Hoji, H., Shibahara, T. and Kadota, K. 2001. Pleomorphic rhabdomyosarcoma in a cow. $J$. Vet. Med. Sci. 63: 107-110.

2. Braun, U. and Ehrensperger, F. 2006. Spinal tumors in three cows. Vet. Rec. 158: 696-698.

3. Chang, H.W., Ho, S.Y., Lo, H.F., Tu, Y.C., Jeng, C.R., Liu, C.H., Wang, F.I. and Pang, V.F. 2006. Vaccine-associated rhabdomyosarcoma with spinal epidural invasion and pulmonary metastasis in a cat. Vet. Pathol. 43: 55-58.

4. Jimma, K., Wada, Y., Ishikawa, Y. and Kadota, K. 1999. Differentiated embryonal rhabdomyosarcoma in a cow. J. Vet. Med. Sci. 61: 577-580.

5. Matsui, T., Imai, T., Han J. S., Awakura, T., Taniyama, H., Osame, S. Nakagawa, M. and Ono, T. 2001. Bovine undifferentiated alveolar rhabdomyosarcoma and its differentiation in xenotransplanted tumors. Vet. Pathol. 28: 438-445.

6. Misdorp, W. 2002 Tumor in calves: comparative aspects. $J$. Comp. Pathol. 127: 96-105.

7. Stober, M. 2002. Tumorkrankheiten der Organe des zentralen Nervensystems. pp. 1165-1169. In: Inner Medizin und Chirurgie des Rindes, 4th ed. (Girksen, G., Grunder, H-D. and Stober M. eds.), Berlin, Germany, Parey Buchverlag,

8. Wagner, W. and Koch, D. 2004. Spinal rhabdomyosarcoma in a child with lipomyelomeningocele. Pediat. Neurosurg. 40: 293-296. 